\title{
WHEN, WHERE, HOW LONG, AND WITH WHOM ARE INDIVIDUALS PARTICIPATING IN PHYSICALLY ACTIVE RECREATIONAL EPISODES?
}

\author{
Ipek N. Sener \\ The University of Texas at Austin \\ Dept of Civil, Architectural \& Environmental Engineering \\ 1 University Station C1761, Austin TX 78712-0278 \\ Phone: 512-471-4535, Fax: 512-475-8744 \\ E-mail: ipek@mail.utexas.edu \\ Chandra R. Bhat (corresponding author) \\ The University of Texas at Austin \\ Dept of Civil, Architectural \& Environmental Engineering \\ 1 University Station C1761, Austin TX 78712-0278 \\ Phone: 512-471-4535, Fax: 512-475-8744 \\ E-mail: bhat@mail.utexas.edu \\ Ram M. Pendyala \\ Arizona State University \\ School of Sustainable Engineering and the Built Environment \\ Room ECG252, Tempe, AZ 85287-5306 \\ Tel: (480) 727-9164; Fax: (480) 965-0557 \\ Email: ram.pendyala@asu.edu
}

July 2009 
Sener, Bhat, and Pendyala

\begin{abstract}
This paper offers a comprehensive analysis of physical recreational activity engagement by simultaneously examining the location, time of day, day of week, and social context of these activities. Data from the 2007 American Time Use Survey is used to estimate a mixed multiple discrete continuous extreme value (MDCEV) model that simultaneously captures the multiple activity categories that people may choose and the time that they allocate to each of the activity categories. It is found that a host of socio-economic, demographic, household, employmentrelated, and environmental variables affect the choice of physical recreational activity engagement with respect to location, time of day, day of week, and social context (with whom the activity is undertaken).
\end{abstract}

Keywords: Physical activity, time use, multiple discrete continuous extreme value model, satiation effects, social network 


\section{INTRODUCTION}

\subsection{Background}

That participation in physical activity is important for the health and well-being of people is a well-established fact. Physical inactivity is strongly correlated with obesity and several diseases including coronary heart disease, colon cancer, nerve disorders, and mental disorders including depression (Struber, 2004; USDHHS, 2008). Regular physical activity enhances muscle and bone strength, decreases body fat, and reduces symptoms of depression and anxiety in humans (USDHHS, 2008; CDC, 2006). Unfortunately, despite campaigns to encourage people to exercise and participate in physically active episodes, almost one-half of adults do not meet recommended levels of physical activity while one-third of adults are categorized as completely inactive (CDC, 2009). The picture is not much better for teenagers and high school students who also show very poor levels of physical activity, with 65.3 percent of high school students not meeting recommended levels of physical activity guidelines (CDC, 2002). More than one-third of adults, or over 72 million people, were obese in 2005-2006 (Ogden, 2007). Among children and teenagers aged 2-19 years, 15.6 percent are categorized as overweight and 16.3 percent as being obese (Ogden, 2008). Obesity is strongly associated with myriad health problems including diabetes, hypertension, cardiovascular disease, strokes, some forms of cancer, sleep apnea, and anxiety (WHO, 2006; Swallen, 2005).

Researchers have established a clear link between physical activity (or, inactivity) and personal health condition (e.g., Haskell et al., 2007; Steinbeck, 2008). In recent years, transportation researchers have been drawn into the study of physical activity engagement patterns of individuals because of the potential association between built environment attributes and levels of physical activity participation. Questions are being asked as to whether the suburban land use configurations marked by sprawl, segregated land use patterns, low density developments, wide streets with poor grid connectivity, and poor non-motorized and transit levels of service are leading to sedentary lifestyles devoid of physical activity, both in the utilitarian (say, bicycling and walking trips undertaken specifically to pursue an activity) and recreational realms (Sallis et al., 2004; TRB, 2005; Killingsworth, 2003).

Numerous studies have been undertaken to examine the influence of built environment variables on physical activity engagement patterns, while controlling for household and personal socio-economic and demographic characteristics (e.g., Huang et al., 2009; Berrigan and Troiano, 
2002; Ewing et al., 2003; Handy et al., 2002). In general, these studies have uniformly found that the built environment does influence physical activity engagement, primarily through enhanced bicycling and walking mode use to undertake daily travel and activities. However, in a recent review, Wendel-Vos et al. (2007) note that a majority of the tested associations between environmental variables and physical activity (recreational physically active episode engagement) were non-significant. Dunton et al. (2008) note that one explanation for this finding is the potentially poor quality of environmental variables used in the studies; it is often difficult to get detailed environmental and contextual variables that characterize the location and timing of individual physical activity episodes. Where studies have found an association between the environment and physically active recreational episode engagement, they have generally been confined to the study of the impacts of providing specific recreational or non-motorized transport facilities in specific locations (e.g., Krizek and Johnson, 2006; Krizek et al., 2007; Dill and Carr, 2003; Merom et al., 2003).

The above discussion points to the high level of interest and research underway in the study of physical activity engagement patterns of individuals among transportation and public health researchers. In addition to correlating physical activity engagement patterns to household and person socio-demographic variables, built environment variables, and specific facility-related impacts, there is a desire and need to better understand physical activity engagement patterns in a more holistic framework. In fact, Dunton et al. (2008) explicitly state that "due to a number of methodological challenges, research to date has been unable to provide a comprehensive description of where and with whom physical activity takes place among US adults”. This has motivated recent research into examining various dimensions of physical activity engagement. Dimensions of interest that describe various facets of physical activity engagement include:

- Nature of the episode, i.e., whether it is a utilitarian active episode or a purely recreational active episode or both

- Location of the episode, i.e., whether the episode is undertaken at home, in an indoor facility outside home, outdoors in open space, or at an outdoor facility

- Timing of the episode, both in terms of time of day and day of week of activity engagement 
- Social context of the episode, i.e., whether the episode is undertaken alone or with others and if others are present, whether the accompanying persons are household members or non-household members (or a mix of both)

- Duration of the episode

A few recent studies by the authors have examined these facets of physical activity engagement, and shed considerable light on the spatial-temporal dimensions of physical activity episodes. Sener and Bhat (2007) examined the social context of children's weekend discretionary activity participation. More recently, Sener et al. (2008) analyzed children’s leisure activity engagement with respect to the day of week, location, physical activity level (whether a passive or active episode), and the temporal and spatial fixity (whether the episode is fixed in time and space). This analysis is quite comprehensive, but misses the social context in which the activities are undertaken and does not address the duration for which the episode occurs. Another paper by Sener et al. (2009a) uses a copula-based approach to model physical activity participation of individuals within family units, thus accounting for intra-household interactions in decisions to engage in physical activity engagement. This is extremely important considering that physical activity (recreational) episodes are often undertaken jointly with other family members. Yet another paper (Sener et al., 2009b) analyzes the spatial and temporal dimensions of recreational activity participation, but does not explicitly consider or model the social context in which these episodes occur. This paper constitutes an attempt to further advance this recent stream of research undertaken by the authors to provide a comprehensive and holistic analysis of physical activity engagement by adults.

\subsection{The Current Paper in Context}

Using data from the American Time Use Survey, the current paper specifically examines the location, timing, duration, and social context of physically active recreational episodes. The analysis is thus limited only in the fact that it considers recreational episodes (and excludes utilitarian travel-related physical activity involving walking and bicycling for a specific trip purpose). In particular, the paper makes a significant contribution to understanding the social context of physical activity engagement, an aspect that has been stressed in the literature, both in the fields of transportation and public health. In the transportation literature, analyzing and modeling intra-household interactions in activity engagement has been recognized as an 
important undertaking. Activity engagement patterns of individuals are influenced by task allocation, joint activity engagement, and activity dependency relationships inherent to any social network (Axhausen, 2005). There are plenty of examples of research studies that document the importance of social networks, social relationships, and intra-household interactions on activity engagement and time use patterns (e.g., Goulias and Henson, 2006; Carrasco and Miller, 2009; Arentze and Timmermans, 2008; Gliebe and Koppelman, 2002; Srinivasan and Bhat, 2008). The social context plays an important role in physical activity engagement due to the inter-personal influences and dependencies that may be at play. If one household member wants to engage in a recreational activity, then that household member may influence other household members to join the activity. Children may be dependent on adults for their ability to access, travel to, and participate in physically active recreational episodes, particularly those located outside home. In fact, Wendel-Vos et al. (2007) note that "social support and having a companion for physical activity were found to be convincingly associated with different types of physical activity including walking, bicycling, vigorous physical activity/sports, leisure time physical activity in general...”.

On a similar note, the spatial and temporal dimensions of physical activity engagement are also important facets that merit further study. Activity-based analysis of travel behavior explicitly recognizes the role of time-space interactions in determining activity-travel choices of individuals (Pendyala et al., 2002). In addition, research has shown that there are systematic tendencies of variability in recreational physical activity engagement between weekdays and weekend days. In general, it has been found that individuals are more likely to engage in physical activity on weekdays than on weekend days (see, for example, Buchowski et al., 2004; Treuth et al., 2007; Behrens and Dinger, 2003), although overweight and obese adults were found to be more active on weekend days than on weekdays (Young et al., 2009). An understanding of the time-space dimensions and day of week preferences of individuals for physically active recreational participation can provide valuable insights into the types of interventions that may enhance people's opportunities to engage in such healthy pursuits. In addition, such insights can help inform the specification and design of activity-based model systems sensitive to a wide range of public health and physical activity related policy questions.

Motivated by the above discussion, this paper uses data from the 2007 American Time Use Survey (ATUS) to model physically active recreational activity participation of adults in a 
holistic framework. Specifically, this paper involves the joint modeling of the duration, location, timing, day of week, and social context of physically active recreational activity engagement. The model formulation adopted in this paper is that of the multiple discrete continuous extreme value (MDCEV) model developed by Bhat $(2005,2008)$ which provides the ability to jointly model the discrete choice dimensions and the continuous time allocation (duration) decision in a simultaneous equations framework.

The next section presents the modeling methodology adopted in this paper. The third section presents a description of the data and the sample used in this study. Model estimation results are presented in the fourth section. Concluding thoughts are offered in the fifth and final section.

\section{MODELING METHODOLOGY}

\subsection{Basic Structure}

This section offers an overview of the MDCEV model structure, which is used to examine adults' physically active recreational activity participation, and time investment, in each “activity day-of-week-location-accompaniment-timing” combination alternative (for ease in presentation, the activity "day of week-location-accompaniment-timing” combination alternatives are simply referred to as activity alternatives in the rest of this paper). The reader is referred to Bhat (2005, 2008) for the intricate details of the model structure.

Let $t_{k}$ be the time invested in activity alternative $k(k=1,2, \ldots, K)$. Consider the following additive, non-linear, functional form to represent the utility accrued by an individual through the time investment vector $\boldsymbol{t}=\left\{t_{1}, t_{2}, \ldots t_{K}\right\}$ in various activity alternatives (the index for the individual is suppressed in the following presentation) ${ }^{1}$ :

$$
U(\boldsymbol{t})=\sum_{k=1}^{K} \frac{1}{\alpha_{k}} \exp \left(\beta^{\prime} z_{k}+\varepsilon_{k}\right)\left\{\left(t_{k}+1\right)^{\alpha_{k}}-1\right\}
$$

$z_{k}$ is a vector of exogenous determinants (including a constant) specific to alternative $k$. The term $\exp \left(\beta^{\prime} z_{k}+\varepsilon_{k}\right)$ represents the random marginal utility of one unit of time investment in alternative $k$ at the point of zero time investment for the alternative. This can be observed by

\footnotetext{
${ }^{1}$ Several other additive, non-linear, utility forms, as proposed by Bhat (2008), were also considered. However, the one provided in Equation (1) was the best form in the empirical analysis of the current paper.
} 
computing the partial derivative of the utility function $U(\boldsymbol{t})$ with respect to $t_{k}$ and computing this marginal utility at $t_{k}=0$ (i.e., $\left.\partial U(\boldsymbol{t}) /\left.\partial t_{k}\right|_{t_{k}=0}\right)$. Thus, $\exp \left(\beta^{\prime} z_{k}+\varepsilon_{k}\right)$ controls the discrete choice participation decision in alternative $k$. This term is referred to as the baseline preference for alternative $k$. $\alpha_{k}\left(\alpha_{k} \leq 1\right)$ is a satiation parameter whose role is to reduce the marginal utility with increasing consumption of alternative $k$, thus reflecting the effects of satiation or diminishing marginal utility with increasing level of participation. When $\alpha_{k}=1$ for all $k$, this represents the case of absence of satiation effects. Lower values of $\alpha_{k}$ imply higher satiation (or lower time investment) for a given level of baseline preference. The constraint that $\left(\alpha_{k} \leq 1\right)$ for $k$ $=1,2, \ldots, K$ is maintained by reparameterizing $\alpha_{k}$ as $\left[1-\exp \left(\lambda_{k}\right)\right]$, where $\lambda_{k}$ is a scalar to be estimated.

From the analyst's perspective, individuals are maximizing random utility $U(t)$ subject to the activity time budget constraint that $\sum_{k} t_{k}=T$, where $T$ is the total time available for adults to participate in physical recreation activities. ${ }^{2}$ The optimal time investments $t_{k}^{*}(k=1,2, \ldots, K)$ can be found by forming the Lagrangian function (corresponding to the problem of maximizing random utility $U(\boldsymbol{t})$ under the time budget constraint $T$ ) and applying the Kuhn-Tucker (KT) conditions. After extensive, but straightforward, algebraic manipulations, the KT conditions collapse to (see Bhat, 2008):

$$
\begin{aligned}
& V_{k}+\varepsilon_{k}=V_{1}+\varepsilon_{1} \text { if } t_{k}^{*}>0(k=2,3, \ldots, K) \\
& V_{k}+\varepsilon_{k}<V_{1}+\varepsilon_{1} \text { if } t_{k}^{*}=0(k=2,3, \ldots, K), \text { where } \\
& V_{k}=\beta^{\prime} z_{k}+\left(\alpha_{k}-1\right) \ln \left(t_{k}^{*}+1\right)(k=1,2,3, \ldots, K) .
\end{aligned}
$$

Assuming that the error terms $\varepsilon_{k}(k=1,2, \ldots, K)$ are independent and identically distributed across alternatives with a type-1 extreme value distribution, the probability that the adult allocates time to the first $M$ of the $K$ alternatives (for duration $t_{1}^{*}$ in the first alternative, $t_{2}^{*}$ in the second, ... $t_{M}^{*}$ in the $M^{\text {th }}$ alternative) is (see Bhat, 2008):

\footnotetext{
2 The analysis is limited to individuals who undertake some amount of physical recreation activity during the sampled day (i.e., only individuals for whom $T>0$ are considered).
} 
$P\left(t_{1}^{*}, t_{2}^{*}, t_{3}^{*}, \ldots, t_{M}^{*}, 0,0, \ldots, 0\right)=\left[\prod_{i=1}^{M} c_{i}\right]\left[\sum_{i=1}^{M} \frac{1}{c_{i}}\right]\left[\frac{\prod_{i=1}^{M} e^{V_{i}}}{\left(\sum_{k=1}^{K} e^{V_{k}}\right)^{M}}\right](M-1) !$

where $c_{i}=\left(\frac{1-\alpha_{i}}{t_{i}^{*}+1}\right)$ for $i=1,2, \ldots, M$.

\subsection{Mixed MDCEV Structure and Estimation}

The structure discussed thus far does not consider correlations among the error terms of the alternatives in the specification of the baseline preference. On the other hand, it is possible that such correlations exist due to factors unobserved by the analyst. For instance, some adults may be more likely to participate in physically active recreation alone or at a certain time of a day such as the morning. Alternatively, some other adults might have a higher propensity to engage in physically active recreational activities at a certain activity location type such as an outdoor park on weekends. To account for such effects, an error component specific to the baseline preferences of all alternatives including the desired activity dimension is introduced. For instance, the predisposition of adults to participate in physical recreational activities alone can be accommodated through an error component specific to the baseline preferences of all physically active recreational activities that include "alone” dimension (that is, an error term common to all activities pursued alone). It should be noted that one can test for several patterns of error components. Such patterns of error components can be accommodated by defining appropriate dummy variables in the $z_{k}$ vector to capture the desired error correlations, and considering the corresponding $\beta$ coefficients in the baseline preference of the MDCEV component as draws from a multivariate normal distribution. In general notation, let the vector $\beta$ be drawn from $\phi(\beta)$. Then the probability of the observed time investment $\left(t_{1}^{*}, t_{2}^{*}, \ldots t_{M}^{*}, 0,0, \ldots 0\right)$ for the adult can be written as:

$P\left(t_{1}^{*}, t_{2}^{*}, \ldots t_{M}^{*}, 0,0,0 . .0\right)=\int_{\beta} P\left(t_{1}^{*}, t_{2}^{*}, . . t_{M}^{*}, 0,0, . .0 \mid \beta\right) \phi(\beta) d \beta$

where $P\left(t_{1}^{*}, t_{2}^{*}, \ldots, t_{M}^{*}, 0,0, \ldots 0 \mid \beta\right)$ has the same form as in Equation (3). 
The parameters to be estimated in Equation (4) include the mean vector and variance matrix of the $\beta$ vector, and the $\lambda_{k}$ scalars $(k=1,2, \ldots, K)$ that determine the satiation parameters $\alpha_{k}$. The likelihood function in Equation (4) includes a multivariate integral whose dimensionality is based on the number of error components in $\beta$. The parameters are estimated through a maximum simulated likelihood approach using Halton draws (for details, see Bhat, 2003).

\section{DATA AND SAMPLE DESCRIPTION}

\subsection{The Data}

The data for the study are derived from the 2007 American Time Use Survey (ATUS), a national survey sponsored by the Bureau of Labor Statistics (BLS) and conducted/processed by the US Census Bureau (BLS, 2008). The household sample for the ATUS is drawn from the set of households that completed the Current Population Survey (CPS). From each sampled CPS household, the ATUS randomly selects one individual of age 15 or over, and collects information on all in-home and out-of-home activity episodes over the course of a 24-hour period. The respondents are asked to sequentially provide information on each activity they participate in for a 24 hour period beginning at 4:00 AM. Episode-level information collected in the ATUS includes activity purpose, start and end time, location of participation (for example, health center, restaurant, library), and 'with whom' the individual participated in each activity. Data on a host of household and personal socio-economic and demographic variables are also collected.

\subsection{The Sample}

\subsubsection{Background}

The objective of this study is to comprehensively model individuals' physically active recreational activity participation. Specifically, the intent is to model the time spent in physically active recreational activities in an integrated framework that encompasses several dimensions:
1) Activity "location" (spatial context)
2) Activity “accompaniment” (social context)
3) Activity "time-of-day" (temporal context)
4) Activity “day-of-week” (temporal context) 
As mentioned earlier, this paper does not consider or include utilitarian active travel episodes (such as traveling by walk or bicycle to undertake activities) as the factors affecting utilitarian active travel and physically active recreational episodes can be fundamentally different (McCormack et al., 2007; Hoehner et al., 2005). The categories considered for each discrete dimension are as follows:

1) Activity location (spatial context)

a. In-home or yard ("In-home” for brevity)

b. Gymnasiums/health clubs/fitness centers (“Club” for brevity)

c. Outdoors away from home - activities pursued in and around residential neighborhood (such as walking/biking/running without any specific destination) or activities pursued at outdoor recreational areas (“Outdoors” for brevity)

d. Indoors - out-of-home activities pursued at places not open (such as someone else's home, work, school, place of worship, other physical activity recreation centers, sports arenas) ("Indoors” for brevity)

2) Activity with whom (social context)

a. Alone

b. Only with family members (including children, spouse, unmarried partners, parents, siblings, grandchild, etc.)

c. Only with friends (including friends, colleagues, neighbors, co-workers, peers, and other acquaintances)

d. With both family and friends (a combination of family, extended family, and friends) ("Mixed company” for brevity)

3) Activity time-of-day (temporal context)
a. Morning (4 AM -11:59 AM)
b. Afternoon (12:00 PM - 5:59 PM)
c. Evening (6:00 PM - 3:59 AM)

4) Activity day-of-week (temporal context)
a. Weekend
b. Weekday 
Overall, the total physical recreation activity time for each individual is categorized into 96 (2x4x4x3) activity "day of week-location-accompaniment-time of day" alternatives. Thus, the value of $K$ in the model structure presented in the previous section is 96 .

\subsubsection{Sample Formation}

An extensive data preparation process was undertaken for this study. All of the physically active recreational episodes were identified based on the ATUS classification scheme. Activities coded as "participating in sports, exercise and recreation" were chosen for inclusion in this study and only individuals who reported a non-zero time investment for this activity category were included in the analysis. The raw data for these activity episodes were processed to derive time of day, day of week, accompaniment, location, and duration information as described previously. Finally, the time investments across all episodes in the day were aggregated to obtain the total daily time investments in each of the 96 categories. The participation decisions, and the daily time investments, in the 96 categories constitute the dependent variables for the MDCEV model.

\subsubsection{Sample Characteristics}

The final sample extracted for analysis consists of 2147 individuals aged 15 years and over. In the interest of brevity, detailed socio-economic and demographic characteristics are not furnished for this sample in the paper. However, it is sufficient to note that an examination of the sample demographic characteristics indicates that the sample offers appropriate and reasonable levels of variability for variables of interest. Therefore, the focus of this subsection is on the physically active recreational activity engagement patterns of individuals.

Table 1 presents a summary of recreational activity engagement of the sample. The mean activity duration is 105 minutes or $1 \frac{3 / 4}{4}$ hours. The sample is about equally divided between weekday and weekend activity episode engagement. Mean episode duration is longer on weekend days than on weekdays, consistent with expectations. The rest of the table offers insights into recreational activity engagement by the dimensions of interest. For example, 27 percent of respondents report pursuing a recreational activity episode at home. The mean duration for these episodes is 60 minutes. It is found that nearly 81 percent of the 578 individuals who report an in-home physically active recreational episode report only this type of episode and none other type of episode. About 20 percent, however, engage in at least one other 
type of activity alternative. Nearly one-half report undertaking an activity episode alone; however, in comparison to group activities, these solo activities are shortest in average duration. Physical activity episodes undertaken in the morning tend to be slightly longer than those undertaken in the evening, although this statistic does not control for day-of-week effect. An examination of the right hand side of the table clearly shows that substantial percentages of individuals are participating in more than one activity alternative, thus calling for the use of the MDCEV model structure that accommodates a multiple discrete choice process in which individuals choose multiple alternatives from a choice set.

A more detailed analysis of physical recreational activity episode engagement was conducted along the dimensions of interest in this paper. The ensuing table has 96 cells with each cell showing the number of individuals who chose the alternative corresponding to that cell. To keep the presentation simple and streamlined, this table is not provided in this paper. However, the table offers key insights into those alternatives that are chosen more than others. For example, 147 of the 1104 individuals who reported their activity time use patterns on a weekday pursued a physical recreational activity episode alone at-home in the morning. Likewise, 80 individuals reported engaging in a physically active recreational episode on a weekday only with friends outside home at an indoor facility in the afternoon period. For purposes of preparing for model estimation, the sample sizes in each cell were examined carefully to identify any alternatives that were rarely or never chosen. It was found that there were a considerable number of alternatives for which sample sizes were extremely thin. For example, only one person reported a physically active recreational episode on a weekday at a club outside home in the evening with only family members in tow. Many other cells, particularly those pertaining to “club” alternatives and “mixed company” alternatives, revealed very small cell values. Therefore, for purposes of model estimation, several alternatives were aggregated along one or more dimensions to yield a final choice set of 39 alternatives.

\section{MODEL ESTIMATION RESULTS}

The mixed MDCEV model system estimated for this study included a range of socio-economic, demographic, and contextual variables (not built environment attributes, but environmental conditions, survey day, and housing unit characteristics). The final model specification was obtained after an exhaustive iterative process in which model coefficients were examined with 
respect to their intuitive behavioral interpretation, magnitude and signs, and statistical significance. In addition to alternative variable specifications, different error component specifications were also considered to generate covariance patterns in the baseline preference of the MDCEV alternatives. The final model estimation results are presented in Table 2 and the following sections offer a detailed discussion of the key findings.

In particular, Table 2a presents parameter estimates corresponding to the baseline preference utility (the $\beta$ parameter vector in Equation 1), while Table 2b presents the implied satiation parameters (obtained by estimating $\lambda_{k}$ and then obtaining the corresponding $\alpha_{k}$ parameter and its standard error). A blank entry in Table 2a under a particular activity alternative for a particular variable implies that this variable is omitted from the utility specification for that alternative (that is, the alternative constitutes a base alternative about which the impact of the variable on other alternatives should be interpreted). The effects of variables are first identified separately along the day of week, location, with whom, and time-of-day dimensions. Then, any interaction effects of the variables on the physical recreational activity baseline utility for each day of week-location-with whom-time of day combination alternative, over and above the onedimensional day of week-location-with whom-time of day effects, are presented towards the bottom of the table.

\subsection{Baseline Parameter Estimates}

Males are less likely to engage in physically active recreational episodes at home, but more likely to engage in such activities outdoors and on weekend days. They also tend to engage in these activities alone or with friends, although it appears that they are less likely to go to the club or recreation center with friends (in comparison to females). These findings are consistent with expectations and confirm some of the gender differences reported by Srinivasan and Bhat (2008), Dunton et al. (2008), and Carrasco and Miller (2009). Younger individuals, who are likely to be single or in households without children, have a greater proclivity to engage in physically active recreational episodes with friends or in mixed company in the afternoon. Older individuals have a greater tendency to undertake these activities alone (possibly due to a shrinking of social networks), and at locations other than a club or recreation center. Interestingly, those 30-45 years and above show a lower tendency to engage in these activities solely with family members, possibly because they have a wider social network that includes co-workers, friends, and 
neighbors. African-Americans and Asians are less likely to pursue activities outdoors in comparison to Hispanics and Whites; Hispanics show a greater tendency to pursue activities outside home, but in indoor facilities. It is possible that Hispanics have more organized community activities than other ethnic groups contributing to this finding. On the other hand, African Americans may show a lower propensity to undertake physical activities outdoors due to poorer quality of neighborhoods and safety concerns. These results are consistent with those reported by Bennett et al. (2007) and Gordon-Larsen et al. (2000).

Those with a disability are more likely to engage in physically active episodes at home and with family, as one would expect (also reported by Pinjari and Bhat, 2008). Family members can provide them the assistance they need in the home environment. Full time students, who are time constrained, are less likely to engage in physical activities in the morning on weekdays. College students on the other hand are likely to engage in physical activities outside home at a "club”, possibly due to greater access to gym facilities at colleges. They are also more likely to engage in these activities outdoors in the evening, which is consistent with expectations, but less likely to do so with mixed company. It is plausible that college students who live with family continue to engage in activities only with family members and those who do not reside with the immediately family engage in activities solely with friends and room-mates. Those with higher levels of education are more likely to engage in physical activities alone at organized facilities, perhaps reflecting the availability of income to pay for the use of such facilities and the potential presence of time constraints. They are less likely to engage in these activities at home, outside home at indoor facilities, and solely with family, reflecting that those individuals with higher education levels may have broader social networks that include friends and colleagues. Finally, as expected those who are married are more likely to engage in physical activities solely with family or in mixed company, and less likely during the evening hours, possibly due to household constraints and obligations.

Employed individuals are more likely to engage in physical activities on weekdays during the evening (possibly after work), on weekdays at organized recreational facilities, and outside home with mixed company, reflecting a broader social network comprising co-workers and friends. Those who are employed full time are less likely to engage in physical activities on weekdays in the morning, presumably due to work constraints, and more likely to undertake activities on weekend days outside home with family members. If a spouse is employed, 
individuals are less likely to engage in physical recreational activities solely with friends, perhaps to enhance the time available to spend with family members. However, this effect is tempered by the interaction effect wherein individuals with an employed spouse are more likely to engage in such activities with friends on weekday evenings outside home.

The presence of children reduces the likelihood of engaging in physical recreational activities on weekdays in the morning, presumably due to school and household constraints, but increases the likelihood of engaging in these activities with family members in the afternoon (possibly due to child after-school and other family recreational activities). As the number of children increases, activities tend to be done with family or in mixed company, and less so alone on weekends. Lower household incomes are associated with greater engagement alone and outdoors (not in organized facilities of any kind) while higher incomes are associated with a greater tendency to use organized recreational facilities (club) alone and a lower tendency to pursue activities solely with family. It is possible that higher income individuals have a larger social network. Those who have recreational facilities and amenities in the home are less likely to use facilities outside the home and more likely to engage solely with family members, which is intuitive given that home-bound activities are likely to be more family-centric.

During the winter months, individuals are less likely to engage in physical recreational activities outside home, while the trend is reversed in the summer when individuals show a lower propensity to undertake activities in-home. However, family-centric activity engagement tends to show an increase in summer. There is also a regional effect with individuals residing in the south less likely to engage in activities in-home and outdoors. In other words, in the south, the weather is good enough to motivate individuals to get out of the house, but too hot to remain outdoors in the open. Instead, individuals seek to engage in activities in organized recreational facilities or other indoor facilities. On a holiday, individuals are more likely to engage in recreational activities with family.

\subsection{Baseline Preferences, Satiation Effects, Error Components and Data Fit}

The previous discussion presented an interpretation of the impacts of various exogenous variables on physical activity episode engagement choices. This subsection will now focus on additional model parameters that shed considerable light on physical activity participation 
preferences of individuals and speak to the merits of adopting a mixed MDCEV approach for modeling individual physical activity engagement patterns.

\subsubsection{Baseline Preferences}

An examination of the baseline preference constants (not presented in the interest of brevity) show that the general tendencies in the sample are consistent with the trends seen in the descriptive statistics presented in Table 1. All of the baseline preference constants are negative compared to the weekday, in-home, alone, morning activity category indicating a higher participation level along these dimensions. Indeed, the descriptive statistics show that there is a higher participation rate and average duration for physically active recreational episodes in this category relative to others.

\subsubsection{Satiation Effects}

Estimates of the satiation parameters are furnished in Table 2b. These correspond to the estimated values of $\alpha_{k}$ in Equation 1. The t-statistics of the $\alpha_{k}$ parameters are computed for the null hypothesis that $\alpha_{k}=1$, which corresponds to a situation where there are no satiation effects ( $\alpha_{k}$ values close to 1 indicate low satiation, while $\alpha_{k}$ values farther away from 1 indicate high satiation effects). In general, the results reject the null hypothesis of the absence of satiation effects in physical recreational activity participation. The highest satiation level is associated with outdoor physical recreation activities engaged with friends in the afternoon and evening periods of the weekend. Activities of this category tend to have a lower average duration of participation relative to other categories. On the other hand, the lowest satiation level is associated with outdoor physical recreation activities undertaken with friends in the morning time periods of the weekend. It is possible that people enjoy participating in physical recreation activities with friends on weekends, and participating in such activities in the morning provides the ability to spend longer periods of time engaging in the joint activity. In the afternoon and evening, on the other hand, individuals are likely to be time-constrained as they need to return home and take care of household obligations (resulting in the high satiation level for afternoon/evening activities).

Lower satiation levels are also found to be associated with activities undertaken at indoor recreational centers (club) alone, with friends, or with mixed company. Most of these satiation 
effects are not significantly different from one. On the other hand, higher satiation levels are seen for club activities undertaken only with family at all periods of the day on both weekdays and weekend days. It is likely once again that household participation effects place greater satiation effects on activities undertaken only with family members. This can be interpreted in two ways. First, the presence of household constraints and obligations may make it burdensome (add disutility) to engage for long periods of time in an activity, thus introducing higher satiation effects. On the other hand, however, it is also possible that household members have other activities that they would like to undertake as a family, thus decreasing the utility associated with participating in any one single "club" activity for a long period of time. Family members may wish to return home, watch television and have a meal together, play outdoors in the park, and so on. Indeed, it is found that activities undertaken only with family members outdoors have little to no satiation effects (value of effect not significantly different from unity). In general, it is found that individuals show lower satiation effects when participating in activities (outdoors or at “club”) only with friends (at all times of the day) on weekdays. These individuals may not have household and family obligations/constraints and would rather engage in activities with friends than be alone at home, thus contributing to this trend. Overall, it is found that satiation levels vary by activity category, with a majority of the categories showing significant satiation effects. This finding clearly supports the use of the MDCEV model structure that incorporates satiation effects in modeling time allocation to multiple activity categories.

\subsubsection{Error Components}

The final model specification included five error components specific to the out-of-home activity locations and accompaniment dimensions. The five error components and their respective standard deviations and t-statistics are as follows:

- Outdoors:

- Club:

- Indoors:

- With family members only:

- With friends only:
Standard deviation $=1.37(\mathrm{t}$-stat $=5.09)$

Standard deviation $=1.68(\mathrm{t}$-stat $=5.42)$

Standard deviation $=1.75($ t-stat $=6.57)$

Standard deviation $=1.76(\mathrm{t}$-stat $=6.07)$

Standard deviation $=2.12($ t-stat $=6.29)$ 
These results indicate that there are common unobserved factors that predispose individuals to participate in physical recreation activities at specific out-of-home locations. An individual predisposed to undertake physical recreation activities outdoors has a higher propensity to participate in such activities regardless of the day of week, time of day, and social context. This individual, due to unobserved latent factors, is the "outdoor" type of person and will have a tendency to pursue activities “outdoors" regardless of the other dimensions of the activity category. Similar predisposition (or unobserved factors) appears to exist for out-of-home club and indoor facility activities.

With respect to accompaniment, it appears that there are significant unobserved factors that predispose individuals to pursue activities solely with family members or solely with friends regardless of the day of week, time of day, and location. It is possible that individuals who enjoy "family time" and family-oriented activities have a proclivity to engage in such activities regardless of the other dimensions. Similarly, those who enjoy socializing with their friends (and conversely, do not enjoy doing activities alone) are likely to engage in such activities regardless of the other dimensions of the activity category. The presence of unobserved factors describing the predisposition (or personality and preferences) of the individual towards these activity locations and accompaniment arrangements should not be ignored given the high level of statistical significance associated with these error components. These findings strongly support the incorporation of mixing in the MDCEV model specification that accommodates error correlation structures.

\subsubsection{Likelihood-based Measures of Fit}

The log-likelihood value at convergence for the final mixed MDCEV model is -11230.7. The corresponding value for the model with only baseline preference constants and satiation parameters is -11769.3. The likelihood ratio test comparing these two model specifications is 1077, which is substantially larger than the critical chi-square value with 61 degrees of freedom at any level of significance. This finding clearly indicates that the exogenous variables and the error components included in the final model specification significantly contribute to explaining participation in and time allocation to physical recreation activities by day of week, location, accompaniment, and time of day. 


\section{CONCLUSIONS}

This paper presents a comprehensive analysis of physical recreational activity engagement of individuals by examining multiple dimensions of such activity engagement simultaneously. The dimensions of activity engagement examined in this paper include the location of the activity, time of day of the activity, day of week of the activity, and the social context (with whom) of the activity. All of these dimensions play a key role in describing the nature of the physical recreational activities that people undertake on a weekly basis. Although previous research has examined various facets of physical activity engagement, this study is unique in that it examines all of these dimensions simultaneously in a holistic modeling framework.

Using data from the 2007 American Time Use Survey (ATUS), the study involved the estimation of a mixed multiple discrete continuous extreme value (mixed MDCEV) model system to accommodate the fact that individuals may choose to participate in physical recreational activity episodes in a variety of alternative categories defined by day of week, time of day, accompaniment, and location. The mixed MDCEV methodology allows the possibility that individuals may choose multiple activity categories and allocate time to the pursuit of the various activity categories chosen. In addition, the mixed MDCEV incorporates error components that accommodate error correlations across alternatives, thus accounting for unobserved factors that may predispose individuals towards pursuing physical recreational activities along certain dimensions more than others. The mixed MDCEV also incorporates satiation effects, i.e., diminishing marginal utility as one spends longer durations of time at the same activity.

Model estimation results indicated that there are a host of socio-economic, demographic, household, employment, and environmental variables that affect the choice of physical recreational activity engagement. In addition, however, there are significant unobserved effects that predispose individuals to pursue activities outdoors (the "outdoor" type of person) and with either household members only (the "family" type of person) or friends only (the "social" individual). In addition, activity categories varied substantially in their satiation effects, supporting the use of the mixed MDCEV model to incorporate such effects. Activity-based models that purport to simulate the activity-travel patterns of individuals should adopt model specifications that incorporate these types of effects and explicitly recognize the social context of activity engagement (e.g., questions of "with whom" and "for whom" the activity is undertaken). 
The paper offers several key insights into the ways in which physical recreational activity engagement can be enhanced. The finding that there are racial disparities, perhaps due to the quality of residential neighborhoods where minorities live, suggests that civic bodies and public agencies should endeavor to provide appropriate neighborhood facilities (both indoor and outdoor) that are safe and accessible to the residents. Such interventions can enhance the physical recreational activity engagement of individuals in those communities. Workplaces that provide amenities for their employees may find that it is well worth the cost of providing such facilities as time-constrained employees take advantage of such resources to engage in physical recreational activities, enhancing the state of their physical and mental health.

The findings in the paper also confirm the notion that the social context of activity engagement is a key aspect that has often been overlooked in studies of physical activity participation. Model estimation results in this paper showed that there are unobserved effects that predispose individuals towards pursuing physical recreation activities with family or friends. In other words, people are "social beings" and have an inherent preference to pursue physical recreation activities in the company of their social circle (whether that be family or friends). The absence of such a social network may have a detrimental effect on physical activity engagement. It is important for civic groups and bodies to assist individuals who are alone (such as the elderly, divorced, widowed) in developing social networks that can motivate the pursuit of physical recreational activities that enhance the state of their physical and mental well-being. Future research efforts that extend this work to include a full slate of environmental variables including built environment and transportation network attributes would go a long way in further identifying policy interventions that can enhance physical recreational activity engagement among individuals. Data limitations prevented the inclusion of such explanatory variables in this particular study.

\section{ACKNOWLEDGEMENTS}

The authors are grateful to Lisa Macias for her help in formatting this document. 


\section{REFERENCES}

Arentze, T. and H. Timmermans (2008) Social networks, social interactions, and activity-travel behavior: A framework for microsimulation. Environment and Planning B, 35, 10121027.

Axhausen, K.W. (2005) Social networks and travel: some hypotheses. In K. Donaghy, S. Poppelreuter, G. Rudinger (eds.) Social Aspects of Sustainable Transport: Transatlantic Perspectives, Ashgate Publishing, Aldershot, England, Chapter 7, 90-108.

Behrens, T. and K. Dinger, (2003) A preliminary investigation of college students' physical activity patterns. American Journal of Health Studies, 18(2/3), 169-172.

Bennett, G.G., L.H. McNeill, K.Y. Wolin, D.T. Duncan, E. Puleo, and K.M. Emmons (2007) Safe to walk? Neighborhood safety and physical activity among public housing residents. PLoS Medicine, 4(10), e306. doi:10.1371/journal.pmed.0040306.

Berrigan, D. and R.P. Troiano (2002) The association between urban form and physical activity in US adults. American Journal of Preventive Medicine, 23(2S), 74-79.

Bhat, C.R. (2003) Simulation estimation of mixed discrete choice models using randomized and scrambled Halton Sequences. Transportation Research Part B, 37(9), 837-855.

Bhat, C.R. (2005) A multiple discrete-continuous extreme value model: formulation and application to discretionary time-use decisions. Transportation Research Part B, 39(8), 679-707.

Bhat, C.R. (2008) The multiple discrete-continuous extreme value (MDCEV) model: role of utility function parameters, identification considerations, and model extensions. Transportation Research Part B, 42(3), 274-303.

Buchowski, M.S., S. Acra, K. M. Majchrzak, M. Sun, and K.Y. Chen (2004) Patterns of physical activity in free-living adults in the southern United States. European Journal of Clinical Nutrition, 58(5), 828-837.

Bureau of Labor Statistics (BLS) (2008) American time use survey user's guide: understanding ATUS 2003 to 2007, http://www.bls.gov/tus/atususersguide.pdf. Bureau of Labor Statistics, Washington, D.C.

Carrasco, J-A., and E.J. Miller (2009) The social dimension in action: A multilevel, personal networks model of social activity frequency between individuals. Transportation Research Part A, 43(1), 90-104.

CDC (2002) Youth risk behavior surveillance - United States, 2001. Morbidity and Mortality Weekly Report Surveillance Summaries, 51(SS-4), June 28. Centers for Disease Control and Prevention, Atlanta, GA.

CDC (2006) Youth Risk Behavior Surveillance - United States, 2005. Morbidity and Mortality Weekly Report, 55(SS-5), Centers for Disease Control and Prevention, Atlanta, GA.

CDC (2009) U.S. Obesity Trends 1985-2007. Available at: http://www.cdc.gov/obesity/ data/trends.html. Centers for Disease Control and Prevention, Atlanta, GA. 
Dill, J. and T. Carr (2003) Bicycle commuting and facilities in major US cities: if you build them, commuters will use them - another look. Transportation Research Record 1828, 116-123.

Dunton, G.F., D. Berrigan, R. Ballard-Barbash, B.I. Graubard, and A.A. Atienza (2008) Social and physical environments of sports and exercise reported among adults in the American Time Use Survey. Preventive Medicine, 47, 519-524.

Ewing, R., T. Schmid, R. Killingsworth, A. Zlot, and S. Raudenbush (2003) Relationship between urban sprawl and physical activity, obesity, and morbidity. American Journal of Health Promotion, 18, 47-57.

Gliebe, J.P. and F.S. Koppelman (2002) A model of joint activity participation between household members. Transportation, 29, 49-72.

Gordon-Larsen, P., R.G. McMurray, and B.M. Popkin (2000) Determinants of adolescent physical activity and inactivity patterns. Pediatrics, 105(6), e83.

Goulias, K.G. and K.M. Henson (2006) On altruists and egoists in activity participation and travel: who are they and do they live together? Transportation, 33(5), pp. 447462.Handy, S.L., M.G. Boarnet, R. Ewing, and R.E. Killingsworth (2002) How the built environment affects physical activity: views from urban planning. American Journal of Preventive Medicine, 23(2S), 64-73.

Haskell, W.L., I-M. Lee, R.R. Pate, K.E. Powell, S.N. Blair, B.A. Franklin, C.A. Macera, G.W. Heath, P.D. Thompson, and A. Bauman (2007) Physical activity and public health: updated recommendations for adults from the ACSM and the AHA. Circulation, 116, 1081-1093.

Hoehner, C.M., L.K.B. Ramirez, M.B. Elliot, S.L. Handy, and R. Brownson (2005) Perceived and objective environmental measures and physical activity among urban adults. American Journal of Preventive Medicine, 28(2S2), 105-116.

Huang, L., D.G. Stinchcomb, L.W. Pickle, J. Dill, and D. Berrigan (2009) Identifying clusters of active transportation using spatial scan statistics. American Journal of Preventive Medicine, 37(2), 157-166.

Killingsworth, R.E. (2003) Health promoting community design: a new paradigm to promote health and active communities. American Journal of Health Promotion, 17(3), 169-170.

Krizek, K.J. and P.J. Johnson (2006) Proximity to trails and retail: effects on urban cycling and walking. Journal of the American Planning Association, 72(1), 33-42.

Krizek, K.J., A. El-Geneidy, and K. Thompson (2007) A detailed analysis of how an urban trail system affects cyclists' travel. Transportation, 34(5), 611-624.

McCormack, G.R., B. Giles-Corti, and M. Bulsara (2007) The relationship between destination proximity, destination mix, and physical activity behaviors. Preventive Medicine, 46, 3340.

Merom, D., A. Bauman, P. Vita, and G. Close (2003) An environmental intervention to promote walking and cycling - the impact of a newly constructed rail trail in western Sydney. Preventive Medicine, 36(2), 235-242. 
Ogden, C.L., M.D. Carroll, M.A. McDowell, and K.M. Flegal (2007) Obesity Among Adults in the United States-No Statistically Significant Change Since 2003-2004, Data Brief Number 1, Centers for Disease Control and Prevention (CDC), Atlanta, GA, November, 8 pp.

Ogden, C.L., M.D. Carroll, and K.M. Flegal (2008) High body mass index for age among U.S. children and adolescents, 2003-2006. Journal of the American Medical Association, 299(20), 2401-2405.

Pendyala, R.M., T. Yamamoto, and R. Kitamura (2002) On the formulation of time-space prisms to model constraints on personal activity-travel engagement. Transportation, 29(1), 7394.

Pinjari, A.R. and C.R. Bhat (2008) A Multiple Discrete-Continuous Nested Extreme Value (MDCNEV) Model: Formulation and application to non-worker activity time-use and timing behavior on weekdays, Technical paper, Department of Civil, Architectural \& Environmental Engineering, The University of Texas at Austin, August 2008.

Sallis, J.F., L.D. Frank, B.E. Saelens, and M.K. Kraft (2004) Active transportation and physical activity: opportunities for collaboration on transportation and public health research. Transportation Research Part A, 38, 249-268.

Sener, I.N. and C.R. Bhat (2007) An analysis of the social context of children's weekend discretionary activity participation. Transportation, 34(6), 697-721.

Sener, I.N., R.B. Copperman, R.M. Pendyala, and C.R. Bhat (2008) An analysis of children's leisure activity engagement: examining the day of week, location, physical activity level, and fixity dimensions. Transportation, 35(5), 673-696.

Sener, I.N., N. Eluru, and C.R. Bhat (2009a) A copula-based clustered ordered response model system for analyzing physical activity participation of individuals in a family unit. Technical Paper, Department of Civil, Architectural \& Environmental Engineering, The University of Texas at Austin.

Sener, I.N., E. Ferguson, and C.R. Bhat (2009b) Modeling the spatial and temporal dimensions of recreational activity participation with a focus on physical activities. Technical paper, Department of Civil, Architectural \& Environmental Engineering, The University of Texas at Austin.

Srinivasan, S. and C.R. Bhat (2008) An exploratory analysis of joint-activity participation characteristics using the American Time Use Survey. Transportation, 35(3), 301-328.

Steinbeck, K.S. (2008) The importance of physical activity in the prevention of overweight and obesity in childhood: a review and an opinion. Obesity Reviews, 2(2), 117-130.

Struber, J. (2004) Considering physical inactivity in relation to obesity. The Internet Journal of Allied Health Sciences and Practice, 2(1).

Swallen, K.C, E.N. Reither, S.A. Haas, and A.M. Meier (2005) Overweight, obesity and healthrelated quality of life among adolescents: the national longitudinal study of adolescent health. Pediatrics, 115, 340-347. 
TRB (2005) Does the Built Environment Influence Physical Activity? Examining the Evidence. TRB Special Report 282, Transportation Research Board and Institute of Medicine, National Research Council, Washington, D.C.

Treuth, M.S., D. J. Catellier, K. H. Schmitz, R. R. Pate, J. P. Elder, R. G. McMurray, R. M. Blew, S. Yang, and L. Webber (2007) Weekend and weekday patterns of physical activity on overweight and normal-weight adolescents girls. Obesity 15, 1782-1788.

USDHHS (2008) Physical Activity Guidelines for Americans. United States Department of Health and Human Services, Washington, D.C. Available at: http://www.health.gov/ paguidelines/pdf/paguide.pdf.

Wendel-Vos, W., M. Droomers, J. Brug, F. van Lenthe (2007) Potential environmental determinants of physical activity in adults: a systematic review. Obesity Review, 8, 425440.

WHO (2006) Obesity and Overweight. Available at: http://www.who.int/dietphysicalactivity/ media/en/gsfs_obesity.pdf. World Health Organization, Geneva, Switzerland.

Young, D.R., G.J. Jerome, C. Chen, D. Laferriere, and W.M. Vollmer (2009) Patterns of physical activity among overweight and obese adults. Prevention of Chronic Diseases, 6(3), http://www.cdc.gov/pcd/issues/2009/jul/08_0186.htm. 


\section{LIST OF TABLES}

TABLE 1 Descriptive Statistics of Physical Recreational Activity Participation

TABLE 2a The Mixed MDCEV Model Results: Baseline Parameter Estimates

TABLE 2b The Mixed MDCEV Model Results: Satiation Parameters - $\alpha_{k}$ Estimates 
TABLE 1 Descriptive Statistics of Physical Recreational Activity Participation

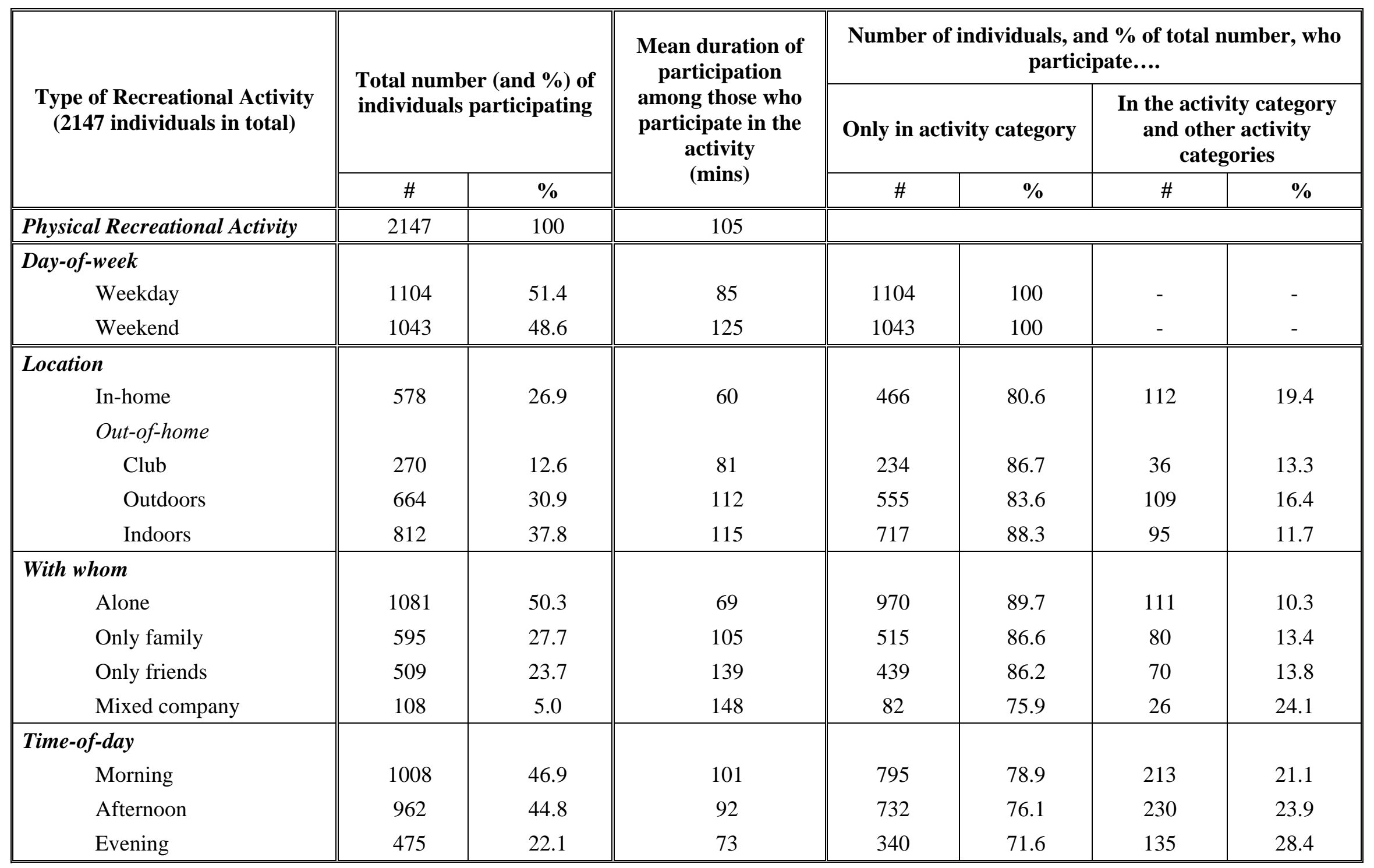


TABLE 2a The Mixed MDCEV Model Results: Baseline Parameter Estimates

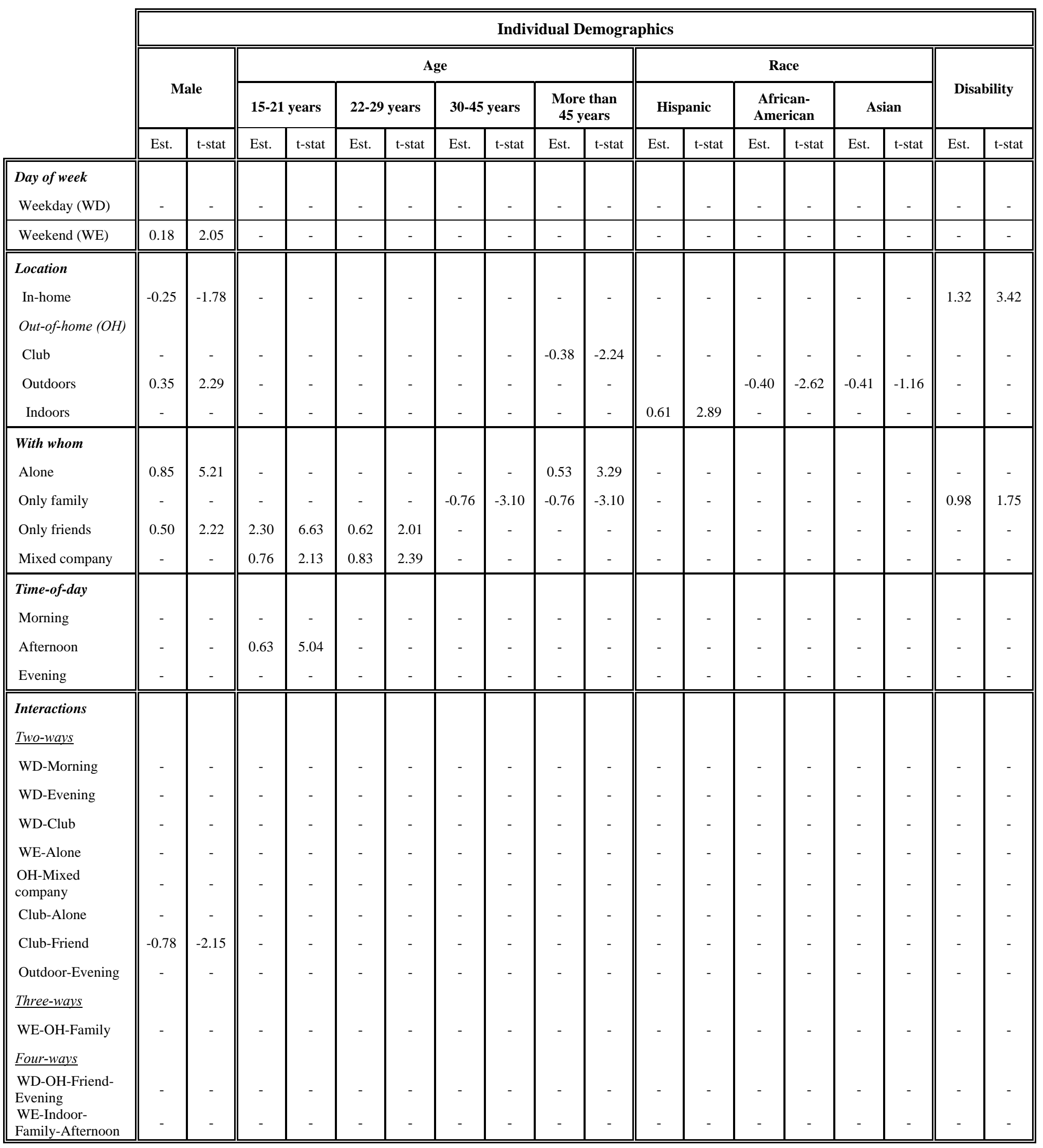


TABLE 2a (Continued) The Mixed MDCEV Model Results: Baseline Parameter Estimates

\begin{tabular}{|c|c|c|c|c|c|c|c|c|c|c|c|c|c|c|c|c|}
\hline & \multicolumn{10}{|c|}{ Individual Demographics } & \multirow{2}{*}{\multicolumn{6}{|c|}{$\begin{array}{c}\text { Employment-related Characteristics } \\
\text { Employment }\end{array}$}} \\
\hline & \multicolumn{4}{|c|}{ Studentship status } & \multicolumn{4}{|c|}{ Education level } & \multirow{2}{*}{\multicolumn{2}{|c|}{ Marital Status }} & & & & & & \\
\hline & \multicolumn{2}{|c|}{$\begin{array}{l}\text { Full-time } \\
\text { Student }\end{array}$} & \multicolumn{2}{|c|}{$\begin{array}{l}\text { College } \\
\text { Student }\end{array}$} & \multicolumn{2}{|c|}{$\begin{array}{c}\text { Some college, } \\
\text { associate or } \\
\text { technical } \\
\text { degree } \\
\end{array}$} & \multicolumn{2}{|c|}{$\begin{array}{c}\text { Bachelor's } \\
\text { degree or } \\
\text { higher }\end{array}$} & & & \multicolumn{4}{|c|}{$\begin{array}{c}\text { Full-time } \\
\text { Employed } \\
(>=30 \text { hours } \\
\text { per week) } \\
\end{array}$} & \multicolumn{2}{|c|}{$\begin{array}{c}\text { Spousal } \\
\text { employment }\end{array}$} \\
\hline & Est. & t-stat & Est. & t-stat & Est. & t-stat & Est. & t-stat & Est. & t-stat & Est. & t-stat & Est. & t-stat & Est. & t-stat \\
\hline \multicolumn{17}{|l|}{ Day of week } \\
\hline Weekday (WD) & - & - & - & - & - & - & - & - & - & - & - & - & - & - & - & - \\
\hline Weekend (WE) & - & - & - & - & - & - & - & - & - & - & - & - & - & - & - & - \\
\hline \multicolumn{17}{|l|}{ Location } \\
\hline In-home & - & - & - & - & - & - & -0.26 & -1.91 & - & - & - & - & - & - & - & - \\
\hline Out-of-home (OH) & & & & & & & & & & & & & & & & \\
\hline Club & - & - & 0.98 & 2.89 & - & - & - & - & - & - & - & - & - & - & - & - \\
\hline Outdoors & - & - & - & - & - & - & - & - & - & - & - & - & - & - & - & - \\
\hline Indoors & - & - & - & - & -0.50 & -3.10 & -0.50 & -3.10 & - & - & - & - & - & - & - & - \\
\hline \multicolumn{17}{|l|}{ With whom } \\
\hline Alone & - & - & - & - & - & - & - & - & - & - & - & - & - & - & - & - \\
\hline Only family & - & - & - & - & -0.58 & -3.08 & -0.58 & -3.08 & 2.53 & 9.13 & - & - & - & - & - & - \\
\hline Only friends & - & - & - & - & - & - & - & - & - & - & 0.24 & 1.25 & - & - & -0.75 & -3.20 \\
\hline Mixed company & - & - & -1.17 & -2.13 & - & - & - & - & 0.70 & 2.39 & - & - & - & - & - & - \\
\hline \multicolumn{17}{|l|}{ Time-of-day } \\
\hline Morning & - & - & - & - & - & - & - & - & - & - & - & - & - & - & - & - \\
\hline Afternoon & - & - & - & - & - & - & - & - & - & - & - & - & - & - & - & - \\
\hline Evening & - & - & - & - & - & - & - & - & -0.33 & -3.68 & - & - & - & - & - & - \\
\hline \multicolumn{17}{|l|}{ Interactions } \\
\hline \multicolumn{17}{|l|}{$\underline{\text { Two-ways }}$} \\
\hline WD-Morning & -0.53 & -2.88 & - & - & - & - & - & - & - & - & - & - & -0.62 & -5.40 & - & - \\
\hline WD-Evening & - & - & - & - & - & - & - & - & - & - & 0.30 & 2.89 & - & - & - & - \\
\hline WD-Club & - & - & - & - & - & - & - & - & - & - & 0.44 & 2.17 & - & - & - & - \\
\hline WE-Alone & - & - & - & - & - & - & - & - & - & - & - & - & - & - & - & - \\
\hline OH-Mixed company & - & - & - & - & - & - & - & - & - & - & 0.87 & 2.30 & - & - & - & - \\
\hline Club-Alone & - & - & - & - & 0.64 & 2.51 & 0.64 & 2.51 & - & - & - & - & - & - & - & - \\
\hline Club-Friend & - & - & - & - & - & - & - & - & - & - & - & - & - & - & - & - \\
\hline Outdoor-Evening & - & - & 0.49 & 1.80 & - & - & - & - & - & - & - & - & - & - & - & - \\
\hline \multicolumn{17}{|l|}{ Three-ways } \\
\hline WE-OH-Family & - & - & - & - & - & - & - & - & - & - & - & - & 0.51 & 3.11 & - & - \\
\hline \\
\hline $\begin{array}{l}\text { WD-OH-Friend- } \\
\text { Evening }\end{array}$ & - & - & - & - & - & - & - & - & - & - & - & - & - & - & 0.47 & 1.96 \\
\hline $\begin{array}{l}\text { WE-Indoor-Family- } \\
\text { Afternoon }\end{array}$ & - & - & - & - & - & - & - & - & - & - & - & - & - & - & - & - \\
\hline
\end{tabular}


TABLE 2a (Continued) The Mixed MDCEV Model Results: Baseline Parameter Estimates

\begin{tabular}{|c|c|c|c|c|c|c|c|c|c|c|c|c|c|c|c|c|c|c|}
\hline & \multicolumn{8}{|c|}{ Household Demographics } & \multicolumn{10}{|c|}{ Physical Environment Factors } \\
\hline & \multicolumn{4}{|c|}{ Children status } & \multicolumn{4}{|c|}{ Household income } & \multirow{2}{*}{\multicolumn{2}{|c|}{$\begin{array}{c}\text { Presence of } \\
\text { amenities in } \\
\text { the house } \\
\text { (lawn, } \\
\text { garden, pool, } \\
\text { etc) }\end{array}$}} & \multicolumn{6}{|c|}{ Seasonal effects and regional characteristics } & \multirow{2}{*}{\multicolumn{2}{|c|}{$\begin{array}{c}\text { Activity day } \\
\begin{array}{c}\text { If the day } \\
\text { was holiday }\end{array}\end{array}$}} \\
\hline & \multicolumn{2}{|c|}{$\begin{array}{l}\text { Presence of } \\
\text { children }\end{array}$} & \multicolumn{2}{|c|}{$\begin{array}{l}\text { Number of } \\
\text { children }\end{array}$} & \multicolumn{2}{|c|}{$\begin{array}{l}\text { Less than } \\
35 \mathrm{~K}\end{array}$} & \multicolumn{2}{|c|}{$\begin{array}{c}\text { Greater than } \\
100 \mathrm{~K}\end{array}$} & & & \multicolumn{2}{|c|}{ Winter } & \multicolumn{2}{|c|}{ Summer } & \multicolumn{2}{|c|}{$\begin{array}{l}\text { Summer- } \\
\text { South }\end{array}$} & & \\
\hline & Est. & t-stat & Est. & t-stat & Est. & t-stat & Est. & t-stat & Est. & t-stat & Est. & t-stat & Est. & t-stat & Est. & t-stat & Est. & t-stat \\
\hline Day of week & & & & & & & & & & & & & & & & & & \\
\hline Weekday (WD) & - & - & - & - & - & - & - & - & - & - & - & - & - & - & - & - & - & - \\
\hline Weekend (WE) & - & - & - & - & - & - & - & - & - & - & - & - & - & - & - & - & - & - \\
\hline Location & & & & & & & & & & & & & & & & & & \\
\hline $\begin{array}{l}\text { In-home } \\
\text { Out-of-home } \\
(\mathrm{OH})\end{array}$ & - & - & - & - & - & - & - & - & - & - & - & - & -0.38 & -2.18 & -0.48 & -2.02 & - & - \\
\hline Club & - & - & - & - & - & - & - & - & -0.72 & -2.80 & -0.76 & -2.93 & - & - & - & - & - & - \\
\hline Outdoors & - & - & - & - & 0.51 & 3.27 & - & - & - & - & -0.57 & -3.05 & - & - & -0.42 & -1.71 & - & - \\
\hline Indoors & - & - & - & - & - & - & - & - & - & - & - & - & - & - & - & - & - & - \\
\hline With whom & & & & & & & & & & & & & & & & & - & - \\
\hline Alone & - & - & - & - & 0.40 & 2.48 & - & - & - & - & 0.19 & 1.20 & - & - & - & - & - & - \\
\hline Only family & - & - & 0.29 & 3.41 & - & - & -0.30 & -1.68 & 0.38 & 1.56 & - & - & 0.69 & 3.85 & - & - & 1.14 & 1.68 \\
\hline Only friends & - & - & - & - & - & - & - & - & - & - & - & - & - & - & - & - & - & - \\
\hline Mixed company & - & - & 0.36 & 3.53 & - & - & - & - & - & - & - & - & - & - & - & - & - & - \\
\hline Time-of-day & & & & & & & & & & & & & & & & & & \\
\hline Morning & - & - & - & - & - & - & - & - & - & - & - & - & - & - & - & - & - & - \\
\hline Afternoon & - & - & - & - & - & - & - & - & - & - & - & - & - & - & - & - & - & - \\
\hline Evening & - & - & - & - & - & - & - & - & - & - & - & - & - & - & - & - & - & - \\
\hline Interactions & & & & & & & & & & & & & & & & & & \\
\hline Two-ways & & & & & & & & & & & & & & & & & & \\
\hline WD-Morning & -0.21 & -2.13 & - & - & - & - & - & - & - & - & - & - & - & - & - & - & - & - \\
\hline WD-Evening & - & - & - & - & - & - & - & - & - & - & - & - & - & - & - & - & - & - \\
\hline WD-Club & - & - & - & - & - & - & - & - & - & - & - & - & - & - & - & - & - & - \\
\hline WE-Alone & - & - & -0.15 & -2.20 & - & - & - & - & - & - & - & - & - & - & - & - & - & - \\
\hline $\begin{array}{l}\text { OH-Mixed } \\
\text { company }\end{array}$ & - & - & - & - & - & - & - & - & - & - & - & - & - & - & - & - & - & - \\
\hline Club-Alone & - & - & - & - & - & - & 0.40 & 1.89 & - & - & - & - & - & - & - & - & - & - \\
\hline Club-Friend & - & - & - & - & - & - & - & - & - & - & - & - & - & - & - & - & - & - \\
\hline $\begin{array}{l}\text { Outdoor- } \\
\text { Evening }\end{array}$ & - & - & - & - & - & - & - & - & - & - & - & - & - & - & - & - & - & - \\
\hline$\underline{\text { Three-ways }}$ & & & & & & & & & & & & & & & & & & \\
\hline WE-OH-Family & - & - & - & - & - & - & - & - & - & - & - & - & - & - & - & - & - & - \\
\hline Four-ways & & & & & & & & & & & & & & & & & & \\
\hline $\begin{array}{l}\text { WD-OH-Friend- } \\
\text { Evening } \\
\text { WE-Indoor- }\end{array}$ & - & - & - & - & - & - & - & - & - & - & - & - & - & - & - & - & - & - \\
\hline $\begin{array}{l}\text { Family- } \\
\text { Afternoon }\end{array}$ & 0.28 & 1.37 & - & - & - & - & - & - & - & - & - & - & - & - & - & - & - & - \\
\hline
\end{tabular}


TABLE 2b The Mixed MDCEV Model Results: Satiation Parameters - $\alpha_{k}$ Estimates $^{3}$

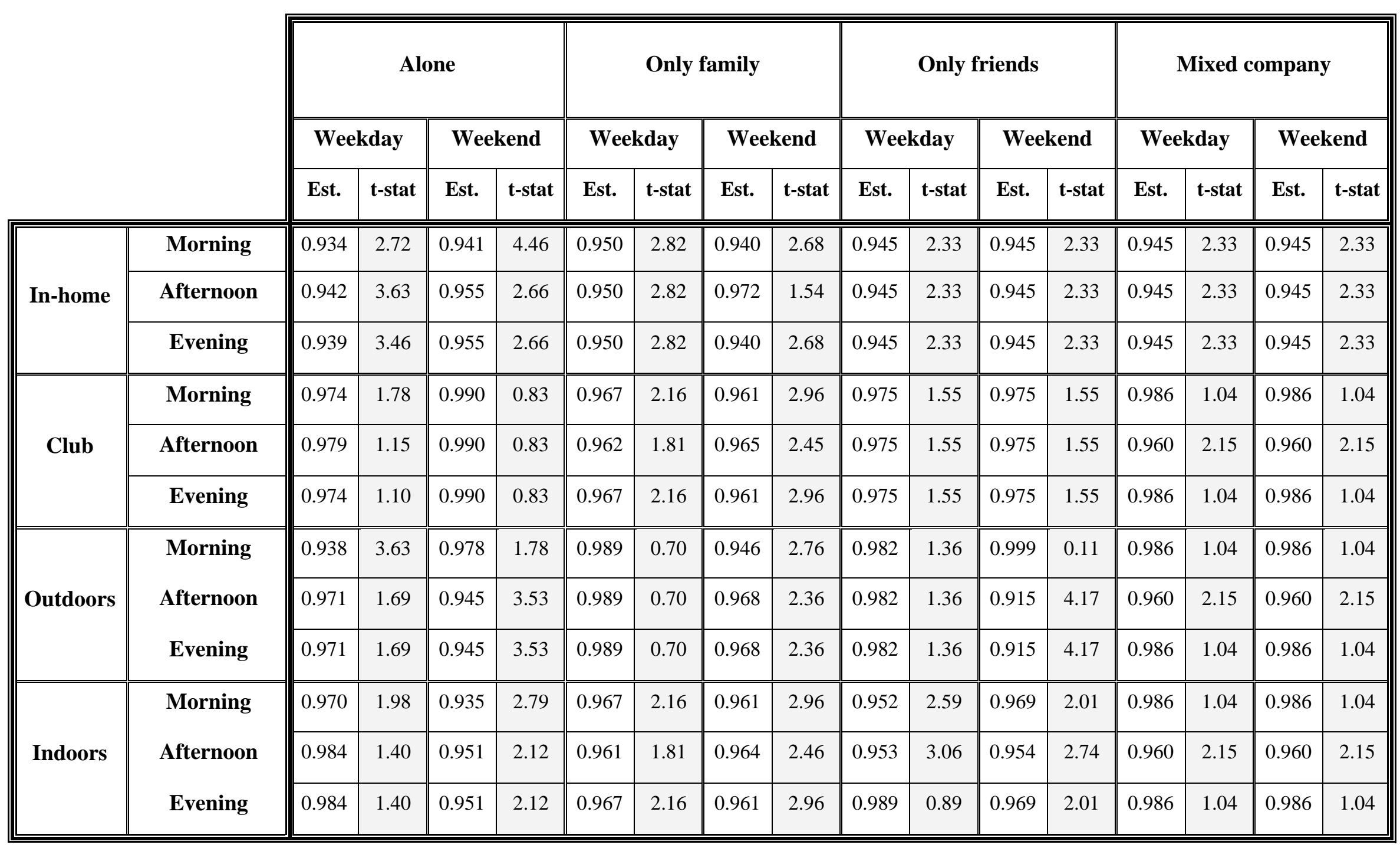

\footnotetext{
${ }^{3}$ The t-statistic is computed for the null hypothesis $\alpha_{k}=1$.
} 